\title{
Preliminary Results from Unsaturated Zone Studies in Unconfined Unconsolidated Coastal Aquifers ${ }^{\dagger}$
}

\author{
Efthymia Zavridou 1, Konstantinos Markantonis ${ }^{1}$, Ioannis Argyrokastritis ${ }^{2}$, \\ Konstantinos Voudouris ${ }^{3}$ and Andreas Kallioras ${ }^{1, *}$ \\ 1 Department of Mining and Metallurgical Engineering, National Technical University of Athens, \\ 15780 Athens, Greece; zavridou@metal.ntua.gr (E.Z.); markantonis@metal.ntua.gr (K.M.) \\ 2 Department of Water Resources Management, Agricultural University of Athens, 11855 Athens, Greece; \\ jarg@aua.gr \\ 3 Department of Geology, Aristotle University of Thessaloniki, 54124 Thessaloniki, Greece; \\ kvoudour@geo.auth.gr \\ * Correspondence: kallioras@metal.ntua.gr; Tel.: +30-210-772-2098 \\ + Presented at the 3rd EWaS International Conference on "Insights on the Water-Energy-Food Nexus", \\ Lefkada Island, Greece, 27-30 June 2018.
}

Published: 31 July 2018

\begin{abstract}
Chloride concentration and salinity tend to vary spatially in depth within the unsaturated zone, according to the local hydrologic conditions; and therefore are widely used as naturally occurring environmental tracers. In this study, undisturbed material from the unsaturated zone was collected at regular intervals of $50 \mathrm{~cm}$ down to a maximum depth of $300 \mathrm{~cm}$ in 17 different locations. Vacuum filtration has been used for extraction of soil water from 75 soil samples, and chemical analyses showed that the chloride concentrations in soils range from 0.4 to $79 \mathrm{meq} / \mathrm{L}$ indicating the existence of soluble salts, also verified by elevated electrical conductivity values.
\end{abstract}

Keywords: unsaturated zone hydrology; direct-push vibro-coring; soil/pore water extraction; multilevel porewater chemistry

\section{Introduction}

The hydrologic zone between soil surface and groundwater table, plays an important role in the recharging of groundwater. Unsaturated zone constitutes a protecting filter for the groundwater by transporting pollutants such as pesticides and fertilizers that might come from the ground surface and contaminating the groundwater. In the unsaturated zone many hydrologic, chemical and biological processes take place simultaneously within different soil horizons. Hence, the soil water and solute transport in the unsaturated zone are components of a complex process.

In order to describe the downward movement of water within the unsaturated zone, the use of naturally occurring or human induced environmental tracers is possible. Different types of environmental tracers can provide different types of information. Natural tracers in hydrological processes research have been useful in determining water pathways, evolution, and age [1-3].

Environmental tracers such as chloride $\left(\mathrm{Cl}^{-}\right)$are produced naturally in the Earth's atmosphere and are used to estimate recharge rates [4,5]. Chloride is a widely used environmental tracer in unsaturated zone hydrologic studies. The movement of chloride within the soil is determined by water fluxes [6] and, especially, the relationship between precipitation and evapotranspiration. Chloride concentrations in a soil profile are determined by pore water.

There are several different water extraction methods currently used to extract water from soil such as vacuum distillation, azeotropic distillation, cryogenic microdistillation, centrifugation, squeezing, leaching and equilibration. This study refers to the development of a methodological 
framework (Figure 1) for investigating the hydrologic processes within the unsaturated zone through a series of field and lab technologies that target at: (i) multi-level undisturbed soil sampling using portable direct-push vibro-coring technologies, (ii) application of porewater extraction techniques for chemical analyses of soil water, and (iii) installation of multi-level continuous pore-water monitoring system.

\section{UNSATURATED ZONE RESEARCH}
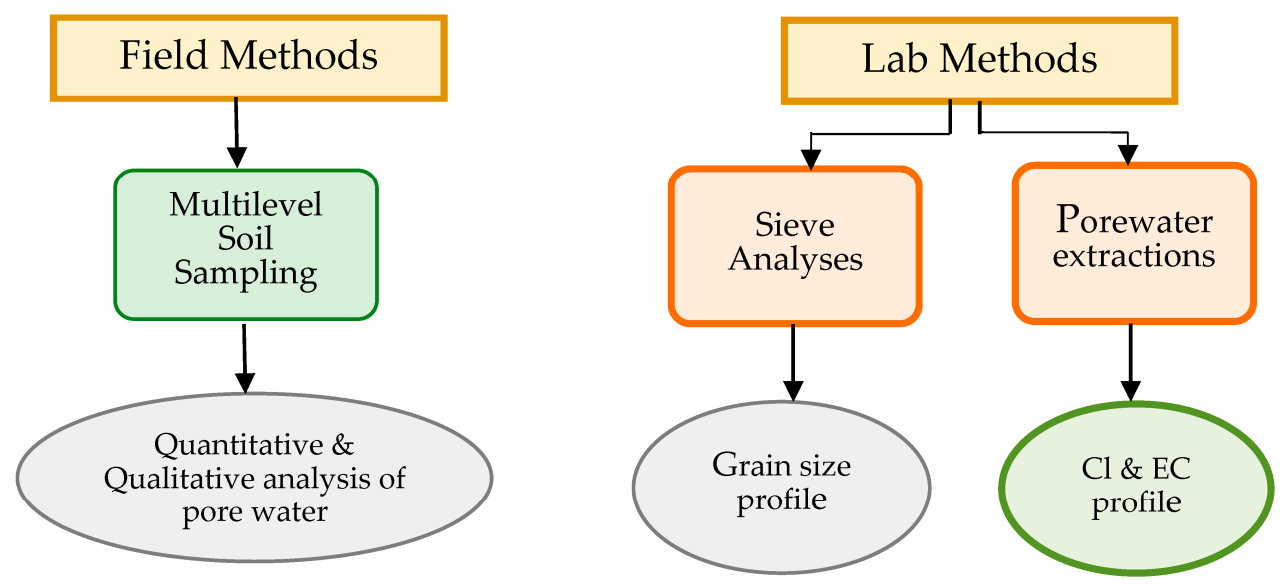

Figure 1. Unsaturated zone research methodological framework.

\section{Site Description}

The study site is located in Marathon plain, in the NE of Attica peninsula, Greece (Figure 2). The site covers an area of $40 \mathrm{~km}^{2}$ and consists of unconsolidated sedimentary deposits. The Marathon plain includes a typical hydrogeological system with an upper unconsolidated formation by alluvial deposits among other aquifer formations. The region has a typical semi-dry Mediterranean climate with wet winters and dry summers. There are many drought periods with relatively low rainfall and high temperatures. The mean annual rainfall from 1987 to 2002 at Marathon plain was estimated at app. $500 \mathrm{~mm}$ and the average annual temperature was $17.1^{\circ} \mathrm{C}$. According to hydrogeological and hydrochemical studies the coastal plain of the basin is influenced by seawater intrusion because of the water demands for agricultural activities are satisfied by the exploitation of groundwater through numerous groundwater wells.

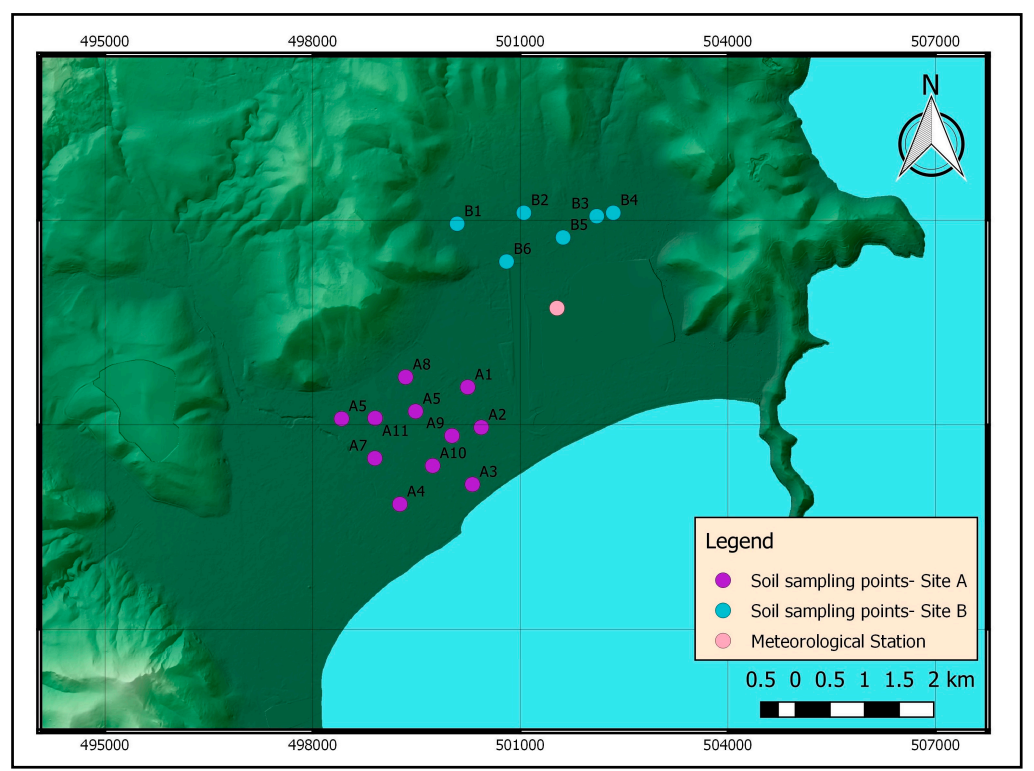

Figure 2. Unsaturated zone measuring points in the coastal hydrosystem of Marathon. 


\section{Materials and Methods}

Samples of unsaturated zone material were taken from the surface to various depths using a portable direct-push vibro-coring set that offered high resolution subsurface investigation and undisturbed soil sampling. Direct push is applicable in unconsolidated sediments, ranging from clay to sand to gravel layers. Hence, a casing is vibrated to penetrate the subsurface using a variable frequency vibrator which is clamped to the outside of a sample liner. When the required depth is reached, the casing with the sampling liner is withdrawn and the liner can be capped for further analysis. No drilling fluids are necessary that would alter water content and water chemistry. Undisturbed soil cores of $50 \mathrm{~mm}$ diameter were sampled at standard intervals of $0.5 \mathrm{~m}$ from the ground surface down to a depth of $3.0 \mathrm{~m}$. The depth of coring was dependent on the efficiency of drilling equipment to core the material encountered. Samples were obtained in April 2017 from 17 different locations within alluvial deposits. At each of the site approximately 500-700 g of sediment were removed and placed in polyethylene bags. Then, the samples were transported to the laboratory for sieve analysis and determination of electrical conductivity and chloride concentrations.

In order to classify different sediments, grain-size analyses were conducted. This method determines the percentage of different grain sizes contained within each horizon of the soil profile. The distribution of particle size larger than 75 micrometers (retained on the No. 200 sieve) was determined by sieving $[7,8]$. Sieving is considered the most widely used method of particle size analysis due the relative simplicity of the technique. The distribution of particle sizes smaller than 75 micrometers was determined by a sedimentation process using a hydrometer $[7,8]$. This method is based on Stoke's law governing the rate of sedimentation of particles suspended in water.

The usual method to quantify chloride concentration and electrical conductivity in soil samples is the saturated paste method because it comes closer to the water content of the soil under field conditions. Water was extracted from the saturated paste samples by vacuum filtration, a technique used to separate solids from liquids. This method requires a Büchner funnel, Büchner flask and a water aspirator assembly (Figure 3). On top of the funnel, a filter paper with the appropriate diameter is placed and wetted with a small amount of the solvent to be used in the filtration. The saturated paste to be filtered is poured onto the filter paper and the vacuum should rapidly pull the liquid through the funnel. The extracted water was collected in bottles and tightly sealed to prevent evaporation. The saturated paste was prepared according to methods for measuring soluble salts by US Salinity Laboratory Staff [9].

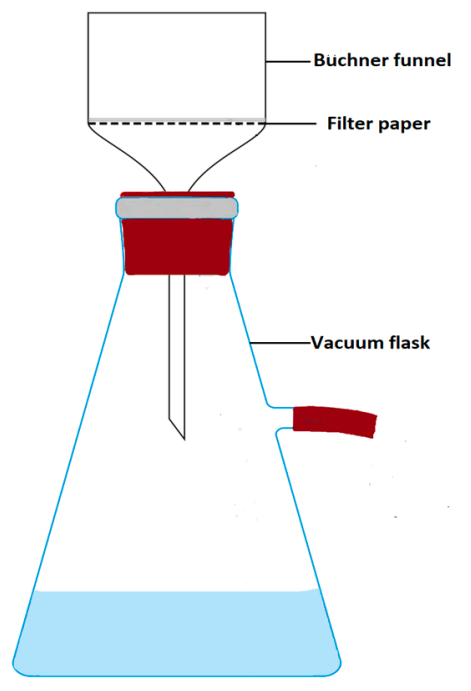

Figure 3. Vacuum filtration apparatus.

The chloride concentration of the extract was measured by a simple titration in accordance with titrate $\mathrm{AgNO}_{3} 2256 \mathrm{~N}$ of $\mathrm{HACH}$. The chloride concentration in extracted water was expressed as meq/L. In addition, to quantify the soluble salts concentration in soils samples the electrical 
conductivity (EC) of the soil water extract was measured with an electrical conductivity meter. The unit most commonly used for EC in soil-water extracts is mmhos $\mathrm{cm}^{-1}$.

\section{Results}

The grain size analyses carried out in three adjacent boreholes for two representative locations and are presented in Figures 4 and 5. The results in Site A showed that soils in the upper $1 \mathrm{~m}$ consist of silt (50-65\%) and sand (32-38\%). The dominant sediments (down to $2.5 \mathrm{~m}$ depth) are gravels $(60 \%)$ while clay is less than 2 percent. In Site B, soils consist mainly of silt (40-70\%) and sand $(20-40 \%)$.
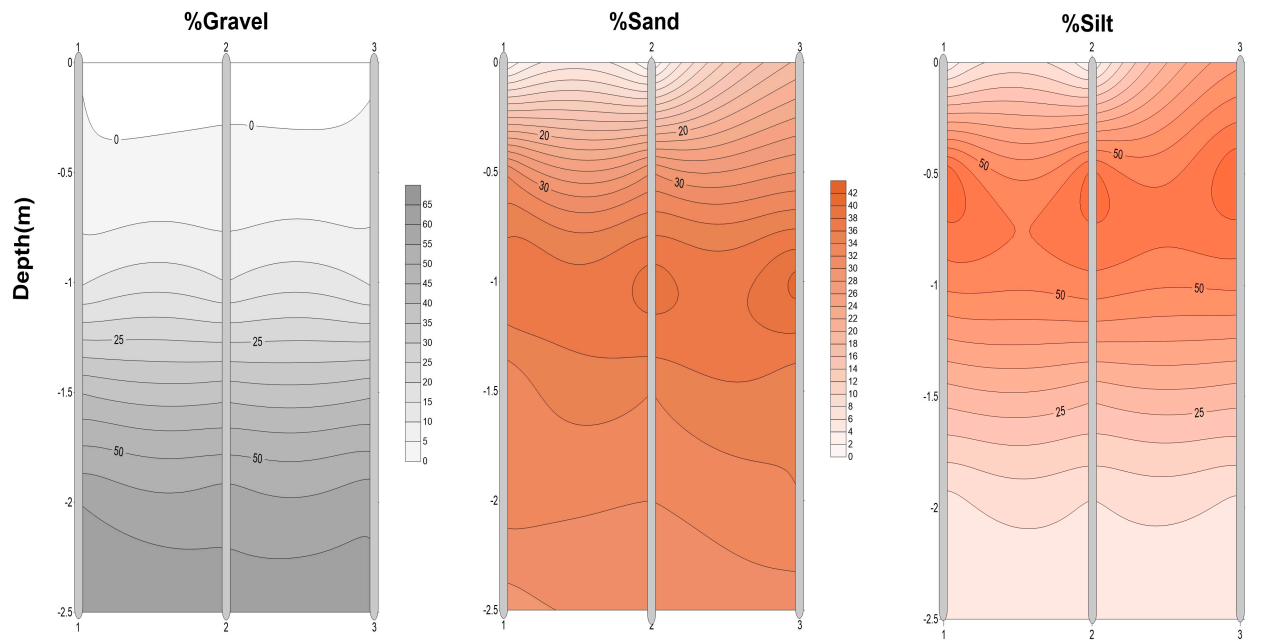

Figure 4. Distribution of grain size analyses-Site A.
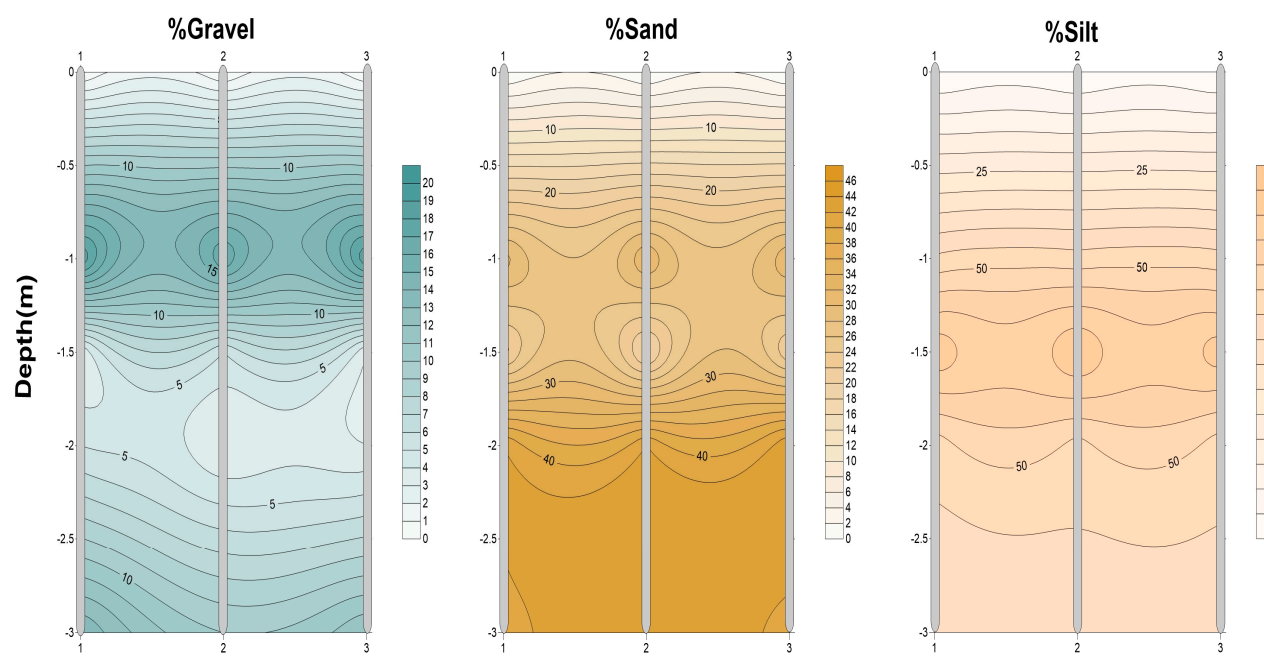

Figure 5. Distribution of grain size analyses-Site B.

The chloride concentration and electrical conductivity values were plotted versus depth in Figures 6-8. The analyses of chloride show a strong variability of solute concentrations. Vertical distribution of chloride concentrations and EC varies significantly within the unsaturated columns of the two selected experimental plots.

Chloride concentration in Site A fluctuates generally within a range of 0.3 to $14.1 \mathrm{meq} / \mathrm{L}$. The highest chloride concentration values (up to $42 \mathrm{meq} / \mathrm{L}$ ) were recorded in sample A2. The significant increase in values in sample A2 is due to the existence of ground water table at $3.5 \mathrm{~m}$ depths. In contrast, the chloride concentration values in the Site B presented significant lower rates up to 4.1 meq/L and increased with depth. This agrees with a model described by Gardner (1967) which predict that under steady-state conditions, where the soil receives chloride in rainfall each year and soil water moves by piston flow, the concentration of chloride in soil water should increase to the bottom of the 
root zone and then remain constant [10]. The presence of chloride peak is widespread in semi-arid areas, which has been shown in numerous localities world-wide [11-14].

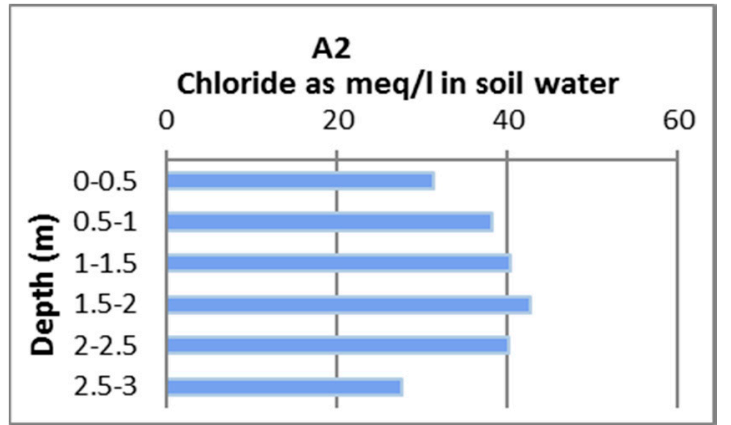

(a)

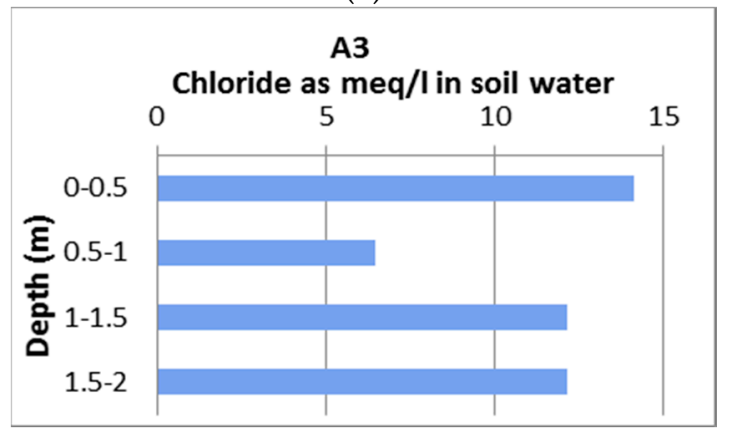

(c)

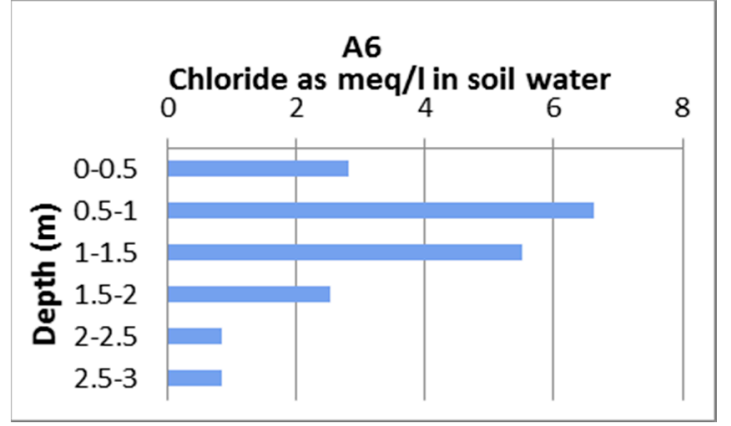

(e)

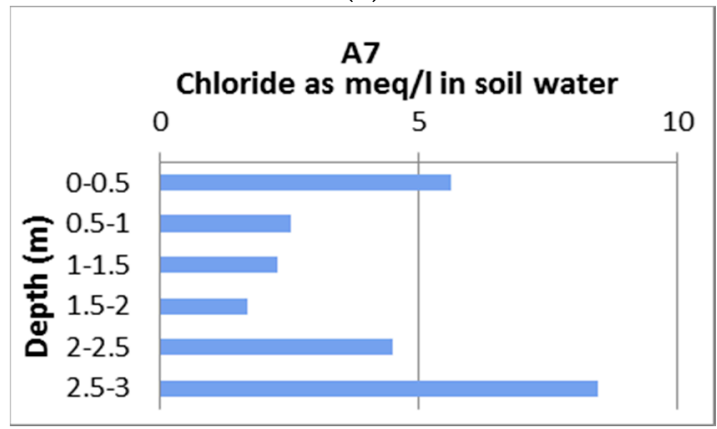

$(\mathrm{g})$

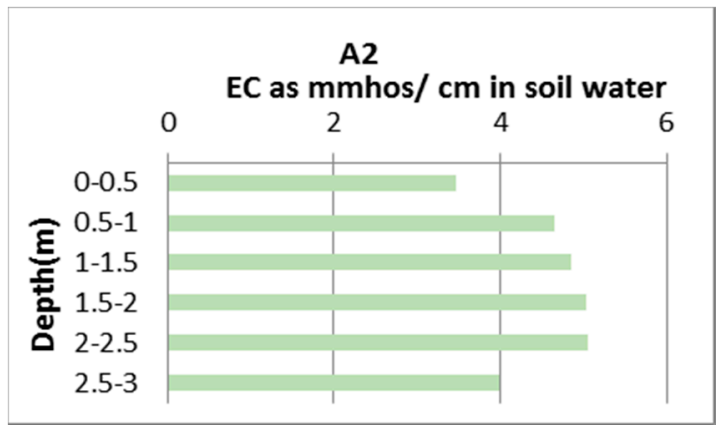

(b)

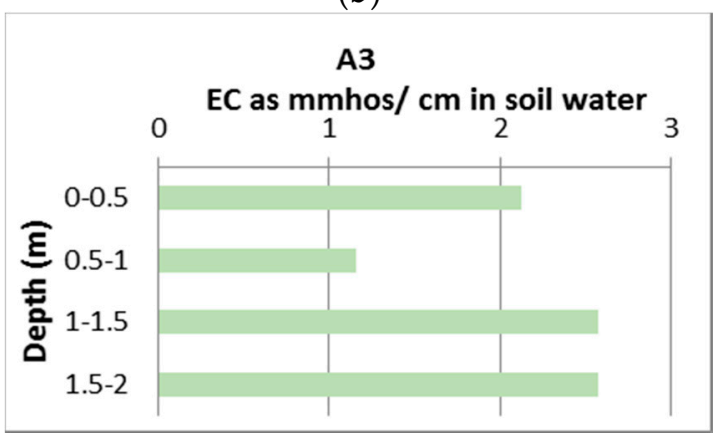

(d)

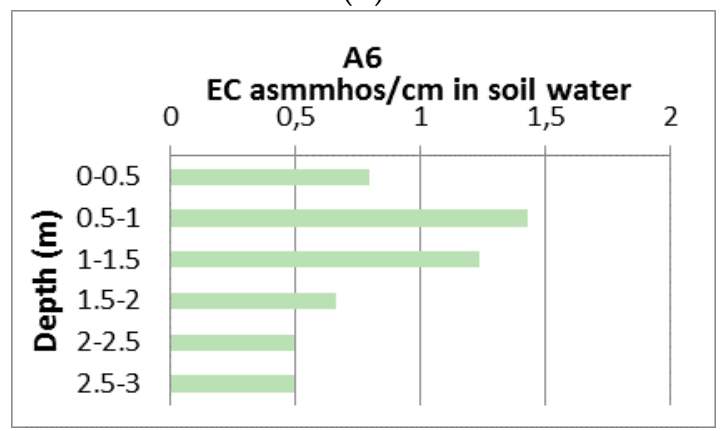

(f)

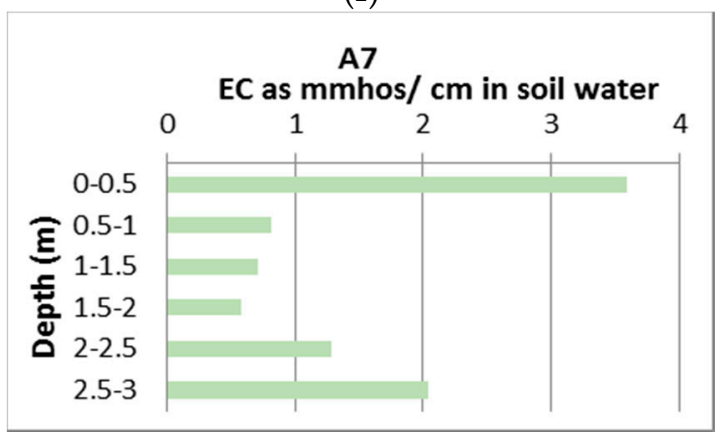

(h)

Figure 6. (a) Chloride concentration in soil water in location A2 (Site A); (b) Electrical conductivity in soil water in location A2 (Site A); (c) Chloride concentration in soil water in location A3 (Site A); (d) Electrical conductivity in soil water in location A3 (Site A); (e) Chloride concentration in soil water in location A6 (Site A); (f) Electrical conductivity in soil water in location A6 (Site A); (g) Chloride concentration in soil water in location A7 (Site A); (h) Electrical conductivity in soil water in location A7 (Site A). 


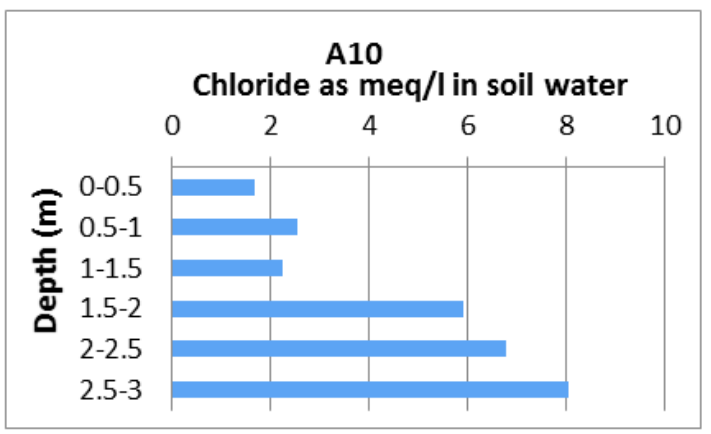

(a)

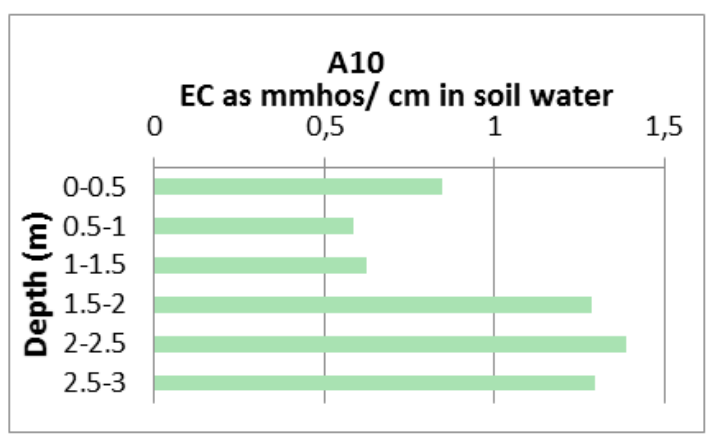

(b)

Figure 7. (a) Chloride concentration in soil water in location A10 (Site A); (b) Electrical conductivity in soil water in site A10 (Site A).

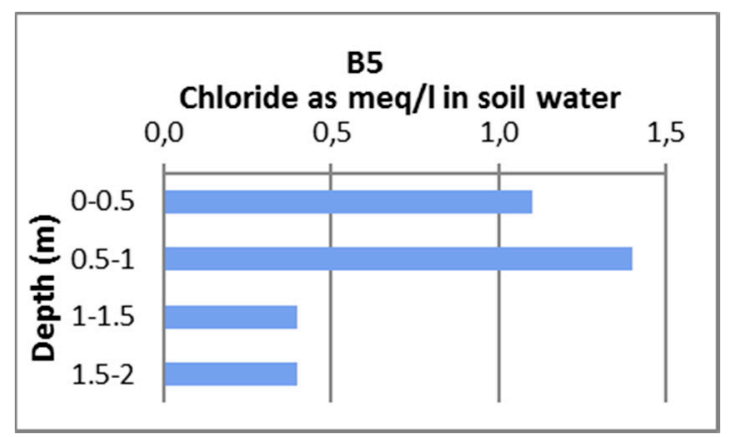

(a)

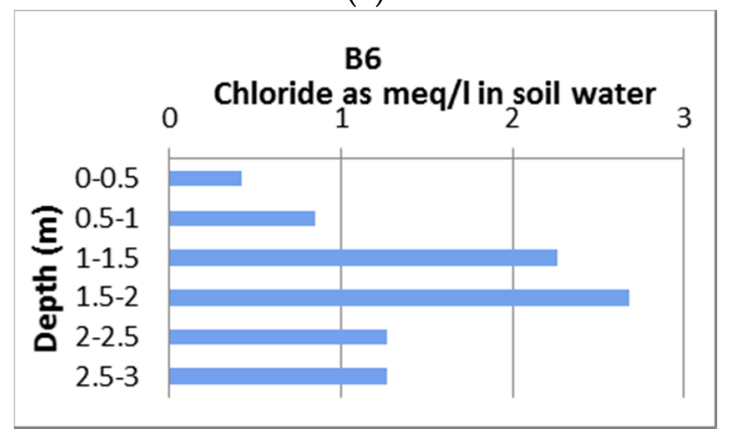

(c)

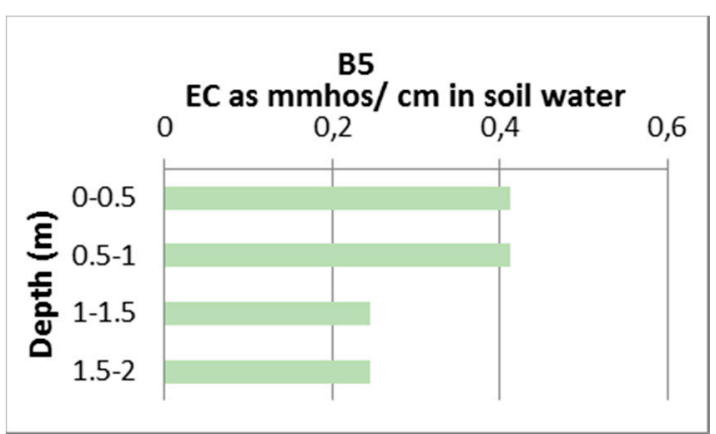

(b)

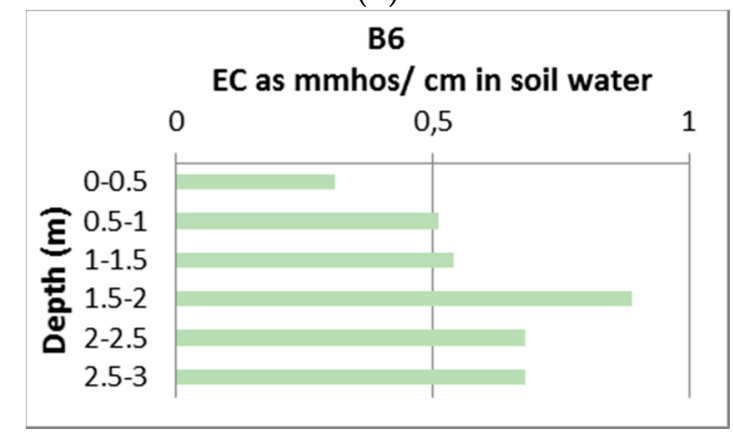

(d)

Figure 8. (a) Chloride concentration in soil water in location B5 (Site B); (b) Electrical conductivity in soil water in location B5 (Site B); (c) Chloride concentration in soil water in location B6 (Site B); (d) Electrical conductivity in soil water in location B6 (Site B).

High chloride concentration values in Site A, indicate low recharge rates because chloride accumulates in the subsurface as a result of evapotranspiration whereas low chloride concentrations indicate high recharge rates because chloride is flushed through the subsurface. These results indicate that recharge through the soil matrix seems to be controlled by soil structure. In addition, human induced practices, such as irrigation and fertilization, contribute significantly to chlorine deposition. Irrigating amounts too low to leach salts, or with water high in salts, allows salts to accumulate in the root zone, increasing the electrical conductivity. The electrical conductivity (EC) values ranged from 0.308 to $10.7 \mathrm{mmhos} / \mathrm{cm}$. According to Dahnke and Whitney (1988), the soil samples in Site A are considered moderately saline (up to $0.5 \mathrm{~m}$ ), slightly saline (0.5-1 m), non-saline (1-2.5 m) and the soil samples in Site B as non-saline (0-3 m) [15]. 


\section{Conclusions}

Preliminary results from this study have proved that chloride concentration values for Site A, are higher than the concentration values in Site B, fact that is attributed to the higher percentage of silt and clay in the soil column of the unsaturated zone, that is believed to be responsible for reduced recharge rates in parts of Marathon plain. The low recharge rates and the large water-holding capacity of the fine textured soil have led to higher chloride concentrations within the measured soil profile. Due to the inherent silt and clay content, the soils in the area present with low vertical hydraulic conductivity values and therefore significantly higher chloride concentration values. Anthropogenic activities such as extensive application of fertilizers as well as intensive irrigation, also influenced the amounts of chloride deposited to the soil.

This research is part of a methodological framework that is under formation in order to develop a technically sound toolbox for unsaturated zone measurements. In principle, the water trapped in the unsaturated zone represents a historic record of infiltration events potentially enabling a quantification of present and past groundwater recharge. Therefore, we apply a combination of different experimental techniques that are targeted to retrieve the information contained in the unsaturated zone.

Acknowledgments: This research is part of the project SUBSOL-bringing coastal SUBsurface Water SOLutions to the market. SUBSOL has received funding from the European Union's Horizon 2020 research and innovation programme under grant agreement No. 642228.

\section{References}

1. Salem, Z.E.; Sakura, Y.; Aslam, M.A.M. The use of temperature, stable isotopes and water quality to determine the pattern and spatial extent of groundwater flow: Nagaoka area. Jpn. J. Hydrol. 2004, 12, 563-575.

2. Flusche, M.A.; Seltzer, G.; Rodbell, D.; Siegel, D.; Samson, S. Constraining water sources and hydrologic processes from the isotopic analysis of water and dissolved strontium, Lake Junin, Peru. J. Hydrol. 2005, 312, 1-13.

3. Al-Gamal, S.A. An assessment of recharge possibility to North-Western Sahara Aquifer System (NWSAS) using environmental isotopes. J. Hydrol. 2011, 398, 184-190.

4. Allison, G.B.; Hughes, M.W. The use of environmental chloride and tritium to estimate total recharge of an unconfined aquifer. Aust. J. Soil Res. 1978, 16, 181-195.

5. Phillips, F.M. Environmental tracers for water movement in desert soils of the American southwest. Soil Sci. Soc. Am. J. 1994, 58, 15-24.

6. Tisdale, S.T.; Nelson, W.L.; Beaton, J.D. Soil Fertility and Fertilizers, 4th ed.; Macmillan Publishing: New York, NY, USA, 1985.

7. ASTM Standard C136-06. Standard Test Method for Sieve Analysis of Fine and Coarse Aggregates; ASTM International: West Conshohocken, PA, USA, 2006.

8. ASTM Standard D422-63e1. Standard Test Method for Particle-Size Analysis of Soils; ASTM International: West Conshohocken, PA, USA, 2007; doi:10.1520/D0422.

9. US Salinity Laboratory Staff. Diagnosis and Improvement of Saline and Alkali Soils; USDA Agricultural Handbook No. 60; US Government Printing Office: Washington, DC, USA, 1954.

10. Gardner, W.R. Water uptake and salt distribution patterns is saline soils. In Proceedings of the Symposium Isotope and Radiation Techniques in Soil Physics and Irrigation Studies, Vienna, Austria, 12-16 June 1967; pp. 335-340.

11. Allison, G.B.; Huges, M.W. The use of natural tracers as indicators of soil-water movement in a temperate semi-arid region. J. Hydrol. 1983, 60, 157-173.

12. Ma, J.; Edmunds, W.M. Groundwater and lake evolution in the Badain Jaran Desert ecosystem, Inner Mongolia. Hydrogeol. J. 2006, 14, 1231-1243.

13. Gates, J.B.; Edmunds, W.M.; Ma, J.; Scanlon, B.R. Estimating groundwater recharge in a cold desert environment in northern China using chloride. Hydrogeol. J. 2008, 16, 893-910. 
14. Scanlon, B.R. Evaluation of moisture flux from chloride data in desert soils. J. Hydrol. 1991, 128, 137-156.

15. Dahnke, W.C.; Whitney, D.A. 1988. Measurement of Soil Salinity. In Recommended Chemical Soil Test Procedures for the North Central Region; Dahnke, W.C., Ed.; North Dakota Department of Agriculture: Bismarck, ND, USA, 1988; pp. 32-34. Available online: msue.anr.msu.edu/uploads/234/68557/rec_chem_ soil_test_proce55c.pdf (accessed on 30 July 2018).

(C) 2018 by the authors. Licensee MDPI, Basel, Switzerland. This article is an open access article distributed under the terms and conditions of the Creative Commons Attribution (CC BY) license (http://creativecommons.org/licenses/by/4.0/). 